\title{
Conceptual Foundations of the Postmaterialist Paradigm of Science
}

\author{
Yuliia Shabanova \\ Doctor of Philosophical Sciences, Professor, Dnipro University of Technology \\ (Dnipro, Ukraine) \\ E-mail: jshabanova@ukr.net \\ https://orcid.org/0000-0001-5876-4140
}

\begin{abstract}
The purpose of this study is to understand the postmaterialistic paradigm of science in the context of a holistic worldview and evolutionary worldview processes. The cosmological model of Helena Blavatsky, who systematically introduced the symmetric structure of the universe in the form of a hierarchy of mutual-integrational structures of matter of different levels, from crude physical matter to the most subtle, spiritual substance, is the methodological basis of the holistic picture of the world. The unity of the system, according to Blavatsky, is provided by the egregore of the Absolute, approximated by conceptual content to the Transcendent. Accordingly, the absolute foundation of the world is an egregore that emits energy of a higher level than traditional energy sources, limited to the physical picture of the world. The article substantiates the conceptual foundations of the postmaterialistic paradigm of science, based on the achievements of quantum physics, synergetics, eniology and the theory of physical vacuum. The principles of the postmaterialistic paradigm (the ontological principle of holism, the principle of teleological hierarchy, the principle of materialistic-ideal complementarity, the anthropic principle of the predefinition of man and the world, the principle of the spiritual determiner of all theories of being) allowing to change radically the methods of energy use, applying the energy potential of the egregore for subtle, non-material matters of reality to upgrade the energy efficiency taking into account the axiological dominant, are explicated.

Keywords: postmaterialistic paradigm; cosmological model of Blavatsky; quantum physics; synergetics; eniology; theory of physical vacuum; egregore; non-material structures; spiritual determiner
\end{abstract}

Received: September 2, 2018; accepted: October 2, 2018

Philosophy and Cosmology, Volume 22, 2019: 162-173.

https://doi.org/10.29202/phil-cosm/22/15

\section{Introduction}

Science is an integral part of culture. Science was reflecting man's deep-seated need for cognition and widening their knowledge of the world along the way of the very mankind's development. Science happens by means of thinking, as one of the special feature of man. The

(C) Shabanova, Yuliia, 2019 
world does not merely exist with the awakening of consciousness and conscious thought but is aware of its existence. In the event of thinking, the Universe recognizes and realizes itself through the logical arguments, abstract speculations, and mathematical system expressed in the scientific activity of man. Reconstructing Socrates's famous dictum, know thyself and Plato's concept of knowledge as an anamnesis, science relies on the implicit ability of a person to generate knowledge from the very act of thinking, while realizing that knowledge is the process of promoting a knowing subject from ignorance to knowledge, and consequently, the process of completing absolute truth as the ultimate object of knowledge. An example of such knowledge is Wisdom, as an inseparable integrity, as a supra-temporal Truth - the knowledge of the Absolute. The way of mankind is the way of Wisdom's augmentation by means of knowing ourselves through the interaction with the surrounding world, laws of which science is trying to describe. The regularities science attempts to describe depend upon the ontological picture science departs from.

The syncretic ground for Theosophy is ancient wisdom as a wholistic knowledge on the infinite and eternal. It is wider than the reproduction of a specific picture of the world, which is the basis of the science of different epochs. The wisdom kept in ancient teachings, protects the process of getting knowledge from fragmentation and promotes the unification of the entire cognitive experience of mankind into an entire world view corresponding to the evolutionary stage of development.

Speaking of science, we traditionally mean science in the European understanding and as a sphere that rationally and reasonably describes the objective laws of the surrounding world. Results and applied consequences of its discoveries depend on the purpose, method, and application of these descriptions. The $21^{\text {st }}$ century, however, demonstrates the obvious need for a radical change in the scientific paradigm. The evidence of that is confirmed in the concept of the 'challenge and response' by Arnold Joseph Toynbee British philosopher, sociologist, cultural expert of the $20^{\text {th }}$ century, who argued that the development of civilizational processes occurs due to the challenge of the historical situation [Toynbee, 1991].

Toynbee's point of view on history must be supplemented by metahistorical reasons for the paradigmal renewal associated with the evolutionary process of consciousness' development as the substantial ground for the realization of all forms of the Universe.

So, the challenges contemporary world faces, are not only the problems of the destruction of the Earth and the danger of self-destruction of the planetary civilization due to contemporary anthropogenic impact, but also the problems of anthropological nature associated with the crisis of material and pragmatic worldview, calling for the dominant role of the spiritual modes of modern society and man.

It seems that the correspondence of science to modern worldview inquiries, can change the critical situation of modern society and give the man the evolutionary meanings embedded in the paradigm of postmaterialist science. Thus, the purpose of this study is to understand the postmaterialistic paradigm of science in the context of a holistic worldview and evolutionary worldview processes.

To achieve this goal, it is necessary to solve the following problems: to study the research literature on the postmaterialist paradigm of science; to reconstruct the semantic components of the periodization of the formation of science; to explicate the features of modern science; to draw analogies of modern problems of science with theosophical ontological concepts; to generalize the evolutionary features and tasks of the development of science in the $21^{\text {st }}$ century. 


\section{Reflexive field of the postmaterialistic paradigm of science}

Postmaterialistic paradigm of science is associated with the spiritual mode of the research area. Questions of spirituality in science as a construct of the formation of the scientific picture of the world have found their expression in the methodological literature at the end of $20^{\text {th }}$ - beginning of the $21^{\text {st }}$ centuries.

Thus, the German theoretical physicist, the founder of the quantum theory Max Planck, defines faith in the spiritual principle as an epistemological determinant of reality evaluation [Planck, 1945]. The English physicist and mathematician Roger Penrose in his book The Emperor's New Mind says that on the basis of Gödel's theory and Bohr's complementarity principle it is strictly demonstrated that without a certain Higher Power, the emergence of new knowledge explaining the structure of the world is impossible [Penrose, 2014]. In support of this, Niels Bohr argued that "new physics should include consciousness" [Bohr, 2010]. Penrose and S. Hameroff introduce the concept of 'consciousness' into the scientific revolution as a universal category of infinitely extending space-time [Hameroff \& Penrose, 2014]. Nick Herbert, an American philosopher of science, justifies the concept of new physics through the defining role of the category of "consciousness" [Herbert, 1993]. Russian thinker Peter Uspenskiy has anticipated the physical groundings for infinite reality in his work Tertium Organum. The Key to the Riddles of the World, where he describes four-dimensional space as a "new feeling of time: an alive universe. Cosmic consciousness. Reality of the infinite" [Uspenskiy, 1992].

Vladimir Struminsky, prominent Ukrainian scientist in the field of statistical aerodynamics and theory of aircraft engineering, comes to the conclusion (on the basis of analysis of the results of fundamental researches in the $20^{\text {th }}$ century) that there is a spiritual component of the Universe and its unity with the material world in the act of Creativity [Struminsky, 1997]. Vladimir Volchenko, Russian researcher, in his article The Recognition of the Creator by Modern Science indicates that today: "We need a new scientific paradigm that excludes the opposition of the ideal, the spiritual to the material, allowing a union of science and religion. But such an alliance is possible only if the compatibility of scientific thinking with the hypothesis of a "subtle" world and God the Creator is recognized" [Volchenko,1997].

Questions of the postmaterialist paradigm of science are becoming a subject of comprehension of modern scholars of the last decade, such as Jaoude Abou [Abou, 2017]; Aleksandr Andreev and Olga Peregudova [Andreev \& Peregudova, 2018]; Mario Beauregard [Beauregard, 2017]; etc.

\section{Scientific paradigms classification}

One of the most sound classifications of scientific paradigms is the concept of the outstanding Russian scientist, academician of the Russian Academy of Sciences Viacheslav S. Styopin. This well-known philosopher of science considers three main stages of the paradigm shifts of scientific rationality in the form of classics, non-classics, and post-nonclassics [Styopin, 2009].

Classical science was formed by the $17^{\text {th }}$ century on the basis of a mechanistic picture of the world. God was granted the function of the Creator, and the world developed according to internal laws, which become the object of mastering by the scientists. Science, exploring external objects, was aspiring to describe the laws of their existence at the theoretical level based on rational activity. Rationality in the science of this period is a product of the realization of the potential possibilities of the mind, which strives to schematize scientific concepts. 
The characteristic features of classical science are objectivity, reasoning, demonstration and experimental evidence, practical value. Criterion of the truth in scientific knowledge is an experiment. A line is drawn between what one can know and what one can not know. Possibility of the knowable is determined by the rational potential. The unknowable is derived out of the scientific picture of the world, leaving to the Transcendent the sphere of religion and dogmatic faith. The rôle of classical science is the elaboration of fundamental methods of cognition, their concretization and methodological elaboration in a tangible rational and empirical perspective.

At the turn of the $19^{\text {th }}-20^{\text {th }}$ centuries we had qualitative changes in science, which marked the formation of its non-classical period. A number of discoveries, which do not seem to fit the classical paradigm, have changed the overall scientific picture. The intensification of mathematization leads to an increased rôle of abstraction and loss of clarity. The subjective factor is increasingly taken into account in research. A certain influence is exerted also by the philosophy of this period, which is concentrated on the irrational, subjective, unconscious. The cognizing subject in science expands its possibilities, enriching rationality with situational data. So, the features of non-classical science are determined: relativism, indeterminism, evolutionism of systems, subject-object epistemological position, pluralism of scientific methods, creative constructivism. The rôle of science in its non-classical model is the introduction into the scientific area of the subjective beginning, the unfolding of the variability of research scenarios, the undermining of the materialistic basis of science.

Post-nonclassical science is formed in the 70 s of the $20^{\text {th }}$ century under the influence of the development of information technology, genetics and the activization of the rôle of social and human sciences. Ludwig Wittgenstein considers philosophy as a special kind of activity, the purpose of which is seen in the logical explanation of scientific thought. In this case, the positivism that Wittgenstein represented, underestimated the rôle of man and, especially, their spiritual potential in the formation of an integral scientific picture. While the epoch required the gathering of all scientific achievements into a single picture of the meaning of man. Phenomenology, led by Edmund Husserl, tries to explore the pure phenomena of consciousness, bringing consciousness and its immanent acts into autonomous existence. Situation that awaits the resolution of extreme positions in scientific methodology evolves in science. Thus, in post-non-classical epoch the role of science was to develop post-materialistic tendencies that reflect evolutionary processes in understanding of man and the world.

In this regard, the postmaterialistic paradigm of science is considered as the concept of an integral worldview, an alternative to classical science, which left issues of intangible structures beyond its attention. A general analysis of the postmaterialistic tendencies, which were obvious from the second half of the $20^{\text {th }}$ century, has demonstrated three main directions, namely, that an anthropological postmaterialism, is not a fundamentally new worldview, but it acts as an antipode to Darwinism, which emphasized the biological nature of man and the dominance of his physiological needs in evolutionary development.

Anthropological postmaterialism generates social postmaterialism which sets altruism (serving the higher goals of evolution, spirit, transcendental, God) as an alternative to egoism (serving personal goals based on the need to satisfy material and physiological needs and other manifestations of gross egocentrism). Social post-materialism strives to form the principles of existence on the basis of the search for the common goal of the whole society, taking into account the specific capabilities of everyone. Philosophical postmaterialism, that was designed to reveal the universal, essential priorities of the postmaterialistic worldview 
paradigm on the basis of ontologicaly-existential cosmology and anthroposophy, is the grounding for characteristics mentioned above.

The term postmaterialism was introduced into the scientific usage by the American researcher Ronald F. Inglehart in the 80 's of the $29^{\text {th }}$ century [Inglehart, 1971]. He builds his theory grounding the idea that material well-being is not a condition for the happiness of a person whose life should be governed by spiritual values. A similar idea was proposed earlier to the world by Abraham Maslow, whose pyramid of needs is completed by spiritual values in the form of complete self-actualization [Maslow, 1987]. The evidence for this theory is of sociological nature and requires a philosophical and ontological justification, the basis of which can be philosophical postmaterialism, closely related to the latest trends in theoretical physics, which, by virtue of expanding its ideas, goes beyond the limits of the laws of empirical entity. In this regard, the philosophy of science becomes that methodological space which can expand sociological postmaterialism to its metaphysical foundations.

In the postmaterialistic picture of the world, the energy is not only the bearer of physical power (a source of heat, light, etc.), but is also an expresser for the quality of information of structures of a nonphysical nature. The basis of this postmaterialistic paradigm of science is quantum theory, which goes beyond the limits of scientific materialism and represents an evolutionarily new level in the formation of the scientific and philosophical picture of the world.

The second half of the $20^{\text {th }}$ century develops a tendency to accumulate fragmentary knowledge, pointlike problems and fractional directions in science. This concretization of plurality as a loss of integrity was largely predicted by Friedrich Nietzsche in $19^{\text {th }}$ century: "The number of isolated impressions is greater than ever: the cosmopolitanism of languages, literatures, newspapers, forms, tastes, even landscapes ... Impressions are washed away by one another; one instinctively guards against perceiving anything, perceiving deeply" [Nietzsche, 2005]. Predictions of Nietzsche became too explicit in the form of a discursive definition "the mosaic".

French culturologist and thinker, Abraham Moles, managed to find this concept at the appropriate time, expressing the process of loss of integrity due to the domination of the fragmentary, brought to the level of a worldview determinant [Moles, 1973].

Holonomic $^{1}$ (holographic or holistic) approach is based on the concept of integrity which is a condition for the existence of all parts involved in a continuously changeable process. The holistic paradigm considers the physical, astral, mental, spiritual aspects of the system, their interaction and ways of development.

The cosmological model of Helena Blavatsky, who systematically introduced the septenary structure of the universe in the form of a hierarchy of mutually integrational structures of matter of different levels, from crude physical matter to the most subtle, spiritual substance can serve as an ontological basis of such understanding. The unity of the system, according to Blavatsky, is due to the determinant of the Absolute, which is a substantial analogue of the Transcendent. So, the fundamental position of the theosophical cosmology of Blavatsky is presented as follows: "The Omnipresent, the Eternal, the Infinite and the Immutable PRINCIPLE, about which no reasoning is possible, for it exceeds the power of human understanding and can only be belittled by human expressions and assimilations. It is beyond the level and achievement of thought" [Blavatsky, 1992: 48].Thus, the holonomy and holography of the world is ensured, in accordance with the universal principle "ALL IN ALL" [Blavatsky, 1992: 51]. Proceeding from this holographic principle, the quality of the energy of the Absolute is immanently

\footnotetext{
${ }^{1}$ Holonomic — an integral, coherent.
} 
represented in its entirety at any level of its objectification. Thus, the basis of holism is the holographic model of the Universe, which keeps the integrity of all its fragments, the egregore ${ }^{2}$ of which emanates the energy intrinsic to the quality of this or that structure.

\section{Quantum theory}

The emergence and development of quantum theory radically changes the scientific approach. Modern science, "striving to limit descriptions of world structures, provokes outbreaks of cultural self-awareness, pulling people out of material-terrestrial coordinates" [Shabanova, 2017: 32], where consciousness acts as a holographic coordinate capable of realizing the meeting of the Man and the Universe, in accordance with an anthropic principle (Brandon Carter) according to which man and the Universe are mutually determined and interdependent [Carter, 1978: 370]. Similarly, quantum concepts are based on the assertion that the manifestation of consciousness interacts with the physical world at the information level. The apriori form of perception (the object of investigation) depends on the observer himself, that is, the subject of cognition. And although the mechanisms of this interaction have not been sufficiently studied, it is possible to affirm the existence of the quantum-mechanical hypothesis of their interactions with respect to the nature of the relations of consciousness and material objects. Thus, Planck's quantum theory of the portional (quantum) radiation and absorption of energy and the theory of relativity of Einstein (according to which mass is equivalent to energy, and space and time - are interdependent on each other) served as the basis for the formation of a new approach to the scientific picture of the world. It is common to organize the interaction of energies of different levels on the basis of the principles of nonlinearity by introducing unincluded situations and metasystems into the development scenario. Synergetics aims to develop qualitatively new approach to the principles of organization of the system extended to the transcendent-immanent interaction of different-level egregores.

\section{Synergetics}

Synergetics as a scientific term is introduced into scientific circulation at the end of the $20^{\text {th }}$ century (Hermann Haken), relying on the ancient concept of sinergeia (co-action), which was used in the Middle Ages to denote a connection with God. It is the holonomic approach, implying the integrity of the different-level egregores, and intensified the development of synergetics as the methodology of the new paradigm of post-non-classical science. The fundamental difference between synergetics and the classical theory of organization is that it takes into account the principles of the development of hypothetical systems, that is, it gives access to the field of different-level organization systems with higher degree of integration an iccordance to the universal principle to aim to preserve integrity. In this regard, intangible systems (subtle material, spiritual structures) with higher degree of organization, fit into the scenario of self-development. At the same time, the basis for self-organization is the cooperative processes that takes into account both material and non-material (spiritual) structures by means of harmonization of the behavior of a larger number of subsystems or elements.

With the appearance of the work Order out of Chaos by Ilya Prigozhin and Isabelle Stengers we came to the understanding that through the concept of dissipative systems, the significance of fluctuations and the contemplation on the state of bifurcation the essence

${ }^{2}$ Egregor is an energy structure that expresses the quintessence of the content of an object or group of objects in an information field, simply speaking, the energy radiation of an object. 
of the general beginning of integration is revealed [Prigogine \& Stengers, 1987]. And this common principle, following the logic of synergetics, can not be explicated only from the pre-set, linear systems, regularities. This common principle is a universal source of energy, thanks to which the infinity of its realization is ensured. Below are main theses of synergetics related to the postmaterialist paradigm:

1. The genesis of the functioning of complex systems is directly related to the spiritual essence of Being (the Spiritual First Origin).

2. The ability of open systems to cardinal qualitative changes (ultimately - the transformation of material systems into intangible metasystems).

3. Transition of disorder (chaos) to order under condition of external influence of more highly developed structures.

4. A jumplike transition from one quality system to a fundamentally different (from material to spiritual).

5. Acceptance of the randomness factor as a necessity (regularities of higher systems are integrated into the sphere of inferior regularity).

6. Lack of pre-defined modeling of a linear sample (not control of the development of the system, but the assumption of its own unfolding vectors, acceptance of spontaneity of self-development).

7. Development of a topological configuration of the resonance of lower (material or physical) systems with higher (non-material or subtle, extra-physical) by increasing the liminality (increasing qualities above the threshold).

8. Quantum principle of energy distribution - discretisation by means of a cluster of evolutionary possibilities of small systems.

Proceeding from these principles, energy conservation is ensured not by the closure of the system, but by its integrity, ensured by all structures of the universe, forming a single informational field. Holonomy as an expression of the holographic conception of the universe is becoming a subject of comprehension of outstanding theoretical physicists of our time, such as David Bom, Stanislav Grof, Erwin Laszlo. Alexander Prigunov writes: "In his theory of 'holomovement' Bohm assumed that every part of space-time continuum of the world contains the whole order of the universe" [Prigunov, 2012: 33].

In this regard, the energy conservation law formulated in 1961 by the physicist Richard Feynman in the form of the statement that 'there is a certain value called 'energy' that does not change under any transformations taking place in nature" [Feynman, 2017] is under reconsideration. As a form of expression of the egregore of different levels (material and non-material) structures, energy acquires the capacity to transform due to its character of emergency ${ }^{3}$ presenting itself in the fundamentally new qualities of subtle matter. The interconnection of energy between different levels of systems and a single informational field becomes the object of understanding of the fundamentally new field of knowledge Eniology.

\section{Eniology}

In scientific use the term Eniology was introduced in the 90s of the last century by the Russian researcher Firiaz Hantseverov, defining it as follows: "ENIOLOGY" - the science of energy-informational exchange in nature and society (abbreviation 'ENIO' - ENergyInformational Exchange)" [Hantseverov, 1996: 12]. In Ukraine, this line at the same time was developed by Henry Shwebs, who argues that eniology, unlike classical science, which

\footnotetext{
${ }^{3}$ Emergency - features of the system that are not reduceable to the features of its elements.
} 
scope of research is limited by the laws of the physical world, "substantiates the patterns of interaction of the structures of coarse and fine matters, as components of a single informational field (IF)" [Shwebs, 2002: 368].

Eniology broadens the ontological boundaries of the scientific picture of the world to intangible levels and determines the source of spiritual origin as the determinant of the world order. At the same time, the structures of different levels (material and spiritual) in this picture are in expedient interaction. The criterion for determining levels in the concept of eniology is information, as the substance of being, which serves as the basis for the manifestation of the primary cause of energy.

The subject of eniology, according to Henry Shwebs, "is the interactions that reveal the connections of the universe, the Earth, the Human Being and the Society from the position of the rôle of the informational environment and the mutual transitions of various objects as complex systems based on informational field structures that determine the processes of selforganization in them" [Shwebs, 2002: 369]. Defining the methodological basis of enology quantum theory, system approach and synergetics - Schwebs, grants the concept of matter new properties in accordance to the characteristics of the informational-field substance that provides a manifestation of fundamentally new qualities of objects from the electron up to the universe. [Shwebs, 2002: 369]. In the context of the energy-informational paradigm, all systems are open, that ensures the exchange of information between them as radiation and energy consumption. Proceeding from the fact that the ontology of eniology includes the multilevel structure of matter, which is not limited to solid forms, but expands to the characteristics of matter, field and consciousness (subtle energy) interacting with each other, the energy category is treated as a form of information transfer, or as a means of information exchange (content) at different levels of structure - material, subtle and immaterial (spiritual).

The new quality of energy, like the egregore of fine structures, is most reasonably presented in the modern theory of physical vacuum.

\section{Theory of physical vacuum}

The authors of the theory of physical vacuum are the Russian physicists Gennady Shipov and A. Akimov believe that this theory of physical vacuum is not, in fact, a "new theory" but it mainly relies on the development of Enstein's ideas. At the same time, their theory reflects the regular trends in the formation of the postmaterialistic paradigm of science, summarizing the achievements of advanced scientists of the late $20^{\text {th }}$ - early $21^{\text {st }}$ century.

Alexander Prigunov, having devoted his monograph to consideration the new paradigm of science from the standpoint of Theosophy, summarizes the experience of scientists of the late $20^{\text {th }}$ century in the formation of a scientific picture of the world based on the complementarity of the material and spiritual structural levels of being. The researcher writes: "At the end of the twentieth century, attempts were made by individual scientists and research teams to move away from traditional concepts and change the views on Universe and the physical picture of the world, drawing attention to the study of a subtle world based on the laws of energy-informational interaction in Nature. A. Okhatrin developed the hypothesis of the informational-energy field, which carries endless knowledge of the Universe and the Creation" [Prigunov, 2012]. Alexey Dmitriev has demonstrated the manifestation of the New Physical Reality - the Renewed Solar System with new qualities obtained owing to the energy-informational interaction of the planet [Dmitriev, 1995].

Amid the presented scientific intuitions and their systematic realization in scientific concepts, the theory of physical vacuum has significant difference in comparison to all 
previous physical theories. This difference lies in the fact that in the natural scientific picture of the world the determining rôle is assigned to the substance of consciousness (the spiritual principle), which is in direct energy-informational interaction with matter. So, in the physical picture of the world, grounded by Gennady Shipov, there are "subtle material worlds of Higher reality", which are the determining factors in the evolution of matter at all levels, including man [Shipov, 1993: 7]. The scientist has developed the theory of physical vacuum, which allows explaining a number of phenomena and processes unexplained till now by modern science, on the basis of which a new (torsion) conception of science that unites the Spiritual and Material systems of the Universe is proposed. Shipov emphasizes in his monograph Theory of the Physical Vacuum: "It could be assumed that living systems that have very high informativeness and very low energy level can go into the subtle (or spiritual) realm of life. $<\ldots>$ Thus, vitality is a formalized characteristic of spirituality, which makes possible to realize the hierarchy of spiritual essences in the esoteric picture of the world" [Shipov, 1993: 8]. Following the logic of "thinning-down of the structures of reality" the author comes to the assumption of the "Great Void — the Physical Vacuum", which brings his views closer to the ancient oriental teachings, where 'emptiness' is an analogue of the absolute first principle. The hierarchy of structures expressing the degree of 'curvature of emptiness' or 'level of disturbance of space' is crowned by the so-called 'torsion fields' expressing the primary impulse of the torsion field or field of consciousness. A. Prigunov writes: "Seven levels of the reality of the Universe are proved, justified, and mathematically described by G. Shipov, on the basis of the theory of the physical vacuum he created (Fig. 1). They fully correlate with the ancient knowledge of the Absolute 'Nothing' (Divine Monad) and the further structures of unfolding of different-level matter, the primary torsional spiritual fields (the field of Consciousness of the Universe), the physical vacuum (ether), plasma (fire), gas (air), liquid (water), solid body (earth)

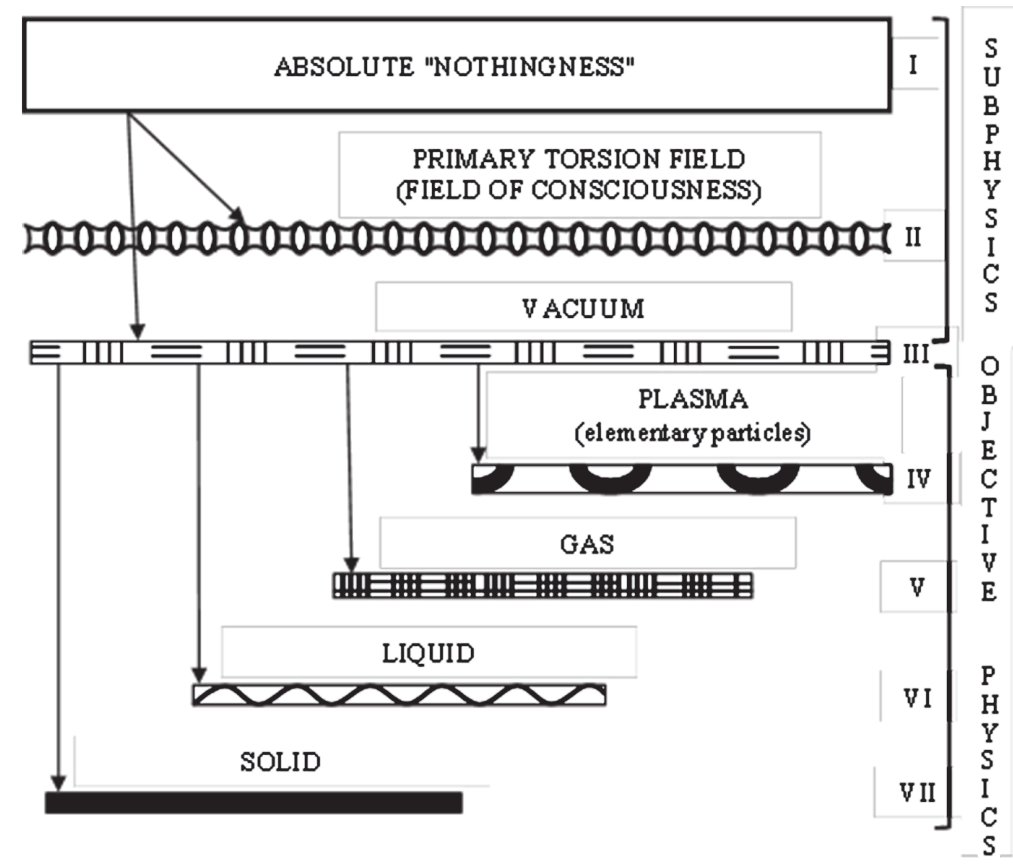

Figure 1. Seven levels of reality by Gennady Shipov 
"The existence of primary torsion fields that have unique properties to transfer information without energy loss with superluminal speed and high penetrating power was found by Gennady Shipov. Acting as primary agents of the absolute vacuum, they generate matter and the informational field" [Prigunov, 2012: 70].

Gennady Shipov points out: "At the first level of reality, the 'primary consciousness' plays a decisive rôle, acting as an active principle, the God, and it can not be described analytically" [Shipov, 1993: 28].

It was found the existence of torsion primary fields in Shipov's theory of physical vacuum. These fields have unique properties to transfer information without energy loss with the superluminal speed and high penetrating power [Shipov, 1993].

\section{Conclusions}

The postmaterialistic paradigm, developed since the late $1980 \mathrm{~s}$ in $20^{\text {th }}$ century, is an evolutionary step in the scientific exploitationof the world, that extends the ontological framework of research to the transcendent determinant and metaphysical structures. Within the framework of the post-materialist paradigm, energy is one of the defining ontological constructs of the world order in the form of the principle of interchange of information of different-level structures of a metaphysical nature. The development of quantum physics has questioned the issue of the material foundation of the world, expanding it to intangible (subtle) levels or "consciousness" as a spiritual determinant of the grosser (material) structures of the world order, which made it possible to base the scientific picture of the world on the following principles:

1. The principle of teleological (appropriately conditioned) hierarchy (from coarse matter to a subtler and, further, to metaphysical and spiritual).

2. The principle of materialistic-ideal complementarity.

3. The anthropic principle of the pre-definition of man and the world.

4. The principle of the spiritual determinant (egregore) of all planes of being.

The basic characteristic of the ontology of post-materialistic science is holism as a concept of the integrity of all forms of the universe, including varieties of both material and intangible structures interacting with each other.

The cosmological model of Helena Blavatsky, who systematically introduced the symmetric structure of the universe in the form of a hierarchy of mutual-integrational structures of matter of different levels, from crude physical matter to the most subtle, spiritual substance, is the methodological basis of the holistic picture of the world. The unity of the system, according to Blavatsky, is provided by the egregore of the Absolute, approximated by conceptual content to the Transcendent. Accordingly, the absolute foundation of the world is an egregore that emits energy of a higher level than traditional energy sources, limited to the physical picture of the world.

The modern development in quantum physics, thanks to which the state of consciousness of the subject of cognition is taken into account in the formalization of research results, serves as a link in the mutual-integrational processes of the different-level structures of the holonomic (holistic) model of the universe. This leads to a radical change in the consumer's goal of applying the results of scientific research and expanding the conceptual inquiry of science.

So, the principle of organizing the interaction of energies of different levels implies overcoming linear modeling, which is due to unincluded metasystems. A qualitatively new approach in the principles of organization of the system extended to the transcendent- 
immanent interaction of different-level egregores allowsto use synergetics as a methodology for non-linear organization of open systems, which, in its turn, allows the metasystems of a higher degree of organization to be admitted into the integration space while maintaining the universal integrity principle. In this connection, intangible systems (subtle, spiritual structures) of a higher degree of organization are potentially interconnected with material structures. Universal characteristics that connect the actualand potential of nonlinear systems are information, as a field substance of being, and energy — the primary impulse of manifestations of informational-field structures.

Energy-informational interaction as a subject of research of eniology (a new type of interdisciplinary knowledge based on a post-materialistic approach in science) of all levels of being is a condition for the realization of universal connections of an infinitely open system.

The modern theory of physical vacuum specifies the eniologic concept of energyinformation interaction, justifying the hierarchy of seven levels of reality organized according to the principle of 'refinement of matter', the highest level of which is represented by 'torsion fields', expressing the primary impulse of the torsion field or the field of consciousness with a high degree of energy. The multi-level structure of subtle plans, as opposed to the law of conservation of energy in classical science, assumes different levels of energy quality depending on the egregore structure. At the same time, the thinner the structure, the more flexible qualities it is endowed with (pervasiveness, speed ofemanation, etc.). As a consequence, the method of obtaining energy is becoming less time consuming and destructive and can be used as an alternative to the extraction of traditional energy carriers.

The postmetarialistic paradigm of science, based on quantum theory, synergetics, eniology and the theory of physical vacuum, has the potential to reveal the high degree of vigor of highly organized intangible structures of the vortex nature without destructive technologies and technogenic interventions in ecological balance. The condition of research and application of the energy of the egregore of the superphysical level is the ontology of holism, based on the energy-information interaction of material and non-material levels of reality, conditioned by the spiritual determinant of the field of 'consciousness'. The implementation of the ontological, epistemological, and axiological foundations of the postmaterialistic paradigm of science and its approaches to optimizing energy efficiency will help to preserve ecological balance and avoid geopolitical tensions in modern society.

\section{References}

Abou, Jaoude. The paradigm of complex probability and analytic nonlinear prognostic for unburied petrochemical pipelines. Systems Science \& Control Engineering. Vol. 5, 2017: 495-534

Andreev, Aleksandr, and Olga Peregudova. Non-linear PI regulators in control problems for holonomic mechanical systems. Systems Science \& Control Engineering. Vol. 6, 2018: 12-19

Beauregard, Mario. The Emerging Post-Materialist Paradigm: Toward the Next Great Scientific Revolution. Interalia Magazine. 2017.

Blavatsky, Helena. The Secret Doctrine. Book.1. Moscow, 1992.

Bohr, Niels. Atomic Physics and Human Knowledge. New York, 2010.

Carter, Brandon. Large number coincidences and the anthropic principle in cosmology. Cosmology. Theory and observation. Moscow, 1978: 369-380.

Dmitriev, Alexey. Mahatmas and the science of the new qualities of the Solar System. Tomsk, 1995. 
Feynman, Richard. Science, non-science and everything, everything, everything. Moscow, 2017.

Hameroff, Stuart, and Roger Penrose. Consciousness in the universe: A review of the 'Orch OR' theory. Physics of Life Reviews. Vol.11 (1), 2014: 39-78.

Hantseverov, Firiaz. Eniology. From intuitive guesses - to modern science. Book. 1. Moscow, 1996.

Herbert, Newhard. Elemental mind: human consciousness and the new physics. New York, 1993.

Inglehart, Ronald. The Silent Revolution in Post-Industrial Societies. American Political Science Review. Vol. 65, 1971: P. 991-1017.

Maslow, Abraham. Motivation and Personality. New York, 1987.

Moles, Abraham. Socio-dynamics of Culture. Moscow, 1973.

Nietzsche, Friedrich. Will to power. Experience of revaluation of all values. Moscow, 2005.

Penrose, Roger, and Martin Gardner. The Emperor's New Mind. New York, 2014.

Planck, Max, Treatise on Thermodynamics. New York, 1945.

Prigogine, Ilya, and Isabelle Stengers. Order from chaos: A new dialogue between man and nature. Moscow, 1986.

Prigunov, Alexander. Modern understanding of the world. Dnepropetrovsk, 2012.

Sarmento, Anabela. Research paradigms and contemporary perspective on humantechnology interaction. Hershey, 2017.

Schwartz, Gary. What is the Nature of a Post-Materialist Paradigm? Three Types of Theories. US National Library of Medicine National Institutes of Health, 2017 https://www. ncbi.nlm.nih.gov/pubmed/26898794

Shabanova, Yuliia. Philosophy and Music. Dnipro, 2017.

Shipov, Gennady. Theory of physical vacuum. Moscow, 1993.

Shwebs, Henry. A short encyclopedic dictionary on eniology. Odessa, 2002. 